\title{
Oxidative Roasting of Low Grade Zinc Sulfide Concentrate from Gagok Mine in Korea
}

\author{
Byung-Su Kim ${ }^{1}$, Soo-Bock Jeong ${ }^{1}$, Young-hun Kim ${ }^{2}$ and Hyung-Seok Kim ${ }^{1, *}$ \\ ${ }^{1}$ Minerals \& Materials Processing Division, Korea Institute of Geoscience \& Mineral Resources, Daejeon, Korea \\ ${ }^{2}$ Research \& Development Team, Korea Resources Corporation, Seoul, Korea
}

\begin{abstract}
A new process for utilizing low grade zinc sulfide concentrate containing a large amount of iron as a zinc and iron resource has been developed in Korea. The process largely consists of oxidative roasting and reduction-volatilization processes. In this process, zinc is recovered as zinc oxide form in the gas phase and iron is concentrated as partially reduced iron oxide compounds in the residue phase. In the present work, a kinetic study on the oxidative roasting of low grade zinc sulfide concentrate rich in iron obtained after several mineral separation processes at Gagok mine in Korea was experimentally investigated. The experiments were carried out to understand the oxidative roasting process of the zinc concentrate over a temperature range of 998 to $1073 \mathrm{~K}$ under air using a thermogravimetric method. The oxidative roasting rate of the zinc concentrate was found to be relatively fast under the whole temperature range and almost $95 \%$ of sulfur contained in the concentrate was removed after the oxidative roasting at $1073 \mathrm{~K}$ for $20 \mathrm{~min}$. Sulfur removal ratio as a function of time has been analyzed by using a spherical shrinking-core model. [doi:10.2320/matertrans.M2010045]
\end{abstract}

(Received February 8, 2010; Accepted May 6, 2010; Published June 30, 2010)

Keywords: zinc sulfide concentrate, oxidative roasting, zinc, shrinking-core model

\section{Introduction}

Zinc metal is produced world-wide from various zinc concentrates and secondary byproducts like lead slag, zinc ash and dross, and EAF dust using hydrometallurgical or pyrometallurgical processes. Among them, more than $80 \%$ of the world's zinc metal output has been produced from zinc sulfide concentrates using hydrometallurgical process which consists of oxidative roasting, sulfuric acid leaching and electrowinning processes. ${ }^{1)}$ In general, it was known that the zinc sulfide concentrates produced over the world for the hydrometallurgical zinc product are high grade concentrates containing $50-55 \%$ for zinc and $1-10 \%$ for iron. ${ }^{1)}$ However, natural zinc sulfide concentrates are becoming more and more complex and low grade since the sources of clean deposits are progressively depleted. As an example, low grade zinc sulfide concentrate containing about $28 \%$ zinc and $21 \%$ iron has been recently obtained after several mineral separation processes at Gagok mine in Korea. At the present time in Korea, zinc sulfide concentrates for the hydrometallurgical zinc product are totally imported from abroad. In the hydrometallurgical process, however, low grade zinc sulfide concentrates containing over $10 \%$ iron cause serious difficulties at the leaching and cementation processes. ${ }^{1-4)}$ Therefore, it would be highly desirable to find an alternative process for a more effective resourcing of such low grade zinc sulfide concentrates, especially when they contain large amount of iron. Technology exists to product zinc from such low grade zinc sulfide concentrates. That is the imperial smelting process (ISP) which is one of the pyrometallurgical zinc product processes. At the present time, only two ISP plants are left in Europe. ${ }^{1)}$ However, the recovery of iron from low grade zinc sulfide concentrates containing large amount of iron by using the ISP is nearly impossible since the

*Corresponding author, E-mail: hskim@kigam.re.kr

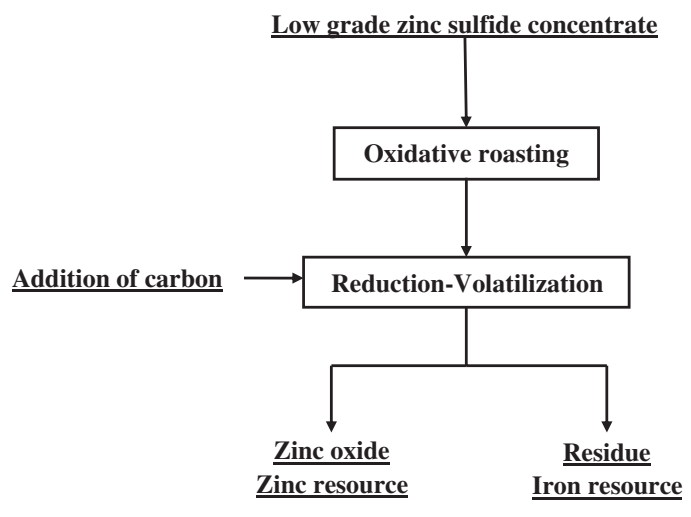

Fig. 1 Flow sheet of a novel process for extracting zinc and iron from low grade zinc sulfide concentrate rich in iron.

slag generated from the ISP contains $6-8 \%$ zinc and $0.5-1 \%$ lead which are very harmful elements in the steelmaking process. $^{5)}$

Keeping these points in mind, the present researchers suggested a new process for a more effective resourcing of the low grade zinc sulfide concentrate produced at Gagok mine in Korea. Figure 1 shows the flow sheet of the suggested process to extract zinc and iron from of the low grade zinc sulfide concentrate, which largely consists of oxidative roasting and reduction-volatilization processes. The process contains the removal of sulfur by oxidative roasting, followed by the reduction-volatilization of the deadroasted concentrate in a furnace, i.e. the process treats the dead-roasted zinc concentrate to produce zinc oxide in the gas phase and partially reduced iron oxide compounds in the residue phase. Thus, the process has a benefit of extracting zinc and iron from low grade zinc sulfide concentrate.

Many researches for the oxidative roasting of zinc sulfide concentrate were performed. ${ }^{6-9)}$ The oxidative roasting of 
zinc sulfide concentrate is one of the important processes in the common hydrometallurgical processes to produce zinc metal. In the roasting process, the sulfur in the zinc sulfide concentrate is removed at temperature around $1223 \mathrm{~K}$ and the zinc sulfide is converted to zinc oxide which is soluble in diluted solution of sulfuric acid. But, in spite of many researches related to the oxidative roasting of zinc sulfide concentrate, sufficient fundamental kinetic data on the oxidative roasting of low grade zinc sulfide concentrate are not available since natural low grade zinc sulfide concentrates are very complicate mineral. In addition, for an optimal design of the new process suggested like Fig. 1 in our research, a detailed investigation of the kinetics under sufficiently wide ranges of the process variables is necessary. Therefore, in the present work, a kinetic study on the oxidative roasting of the natural low grade zinc sulfide concentrate obtained from Gagok mine in Korea was experimentally investigated under isothermal condition in air using TGA equipment.

\section{Experimental Work}

Experiments on the oxidative roasting of low grade zinc sulfide concentrate were carried out in a thermogravimetic analysis (TGA) apparatus similar to the one described in the previous paper. ${ }^{10)}$ The apparatus consisted of a recording microbalance from one arm of which a shallow silica tray for holding low grade zinc sulfide concentrate was suspended by a platinum chain into an Inconel reactor tube located within vertical tubular furnace. By means of a gas delivery system, mass flow controllers of air and nitrogen were also used. The exit gas was cleaned by bubbling it through a $10 \%$ hydrogen peroxide solution in water to remove produced sulfur dioxide gas before being discharged. The gas temperature in the reactor was measured by chromel-alumel thermocouples. The heating rate was fixed at $8 \mathrm{~K} / \mathrm{min}$ until the experimental temperature. A uniform temperature profile of $\pm 4 \mathrm{~K}$ was achieved over $2 \mathrm{~cm}$ length of the reaction tube.

The experiments were performed at temperature ranges between 998 and $1073 \mathrm{~K}$ under air. A sample weight of about $500 \mathrm{mg}( \pm 5 \mathrm{mg})$ of low grade zinc sulfide concentrate was used for each run. During heating, a steady flow of $16.7 \mathrm{~mL} / \mathrm{s}$ of dry air was maintained through the reactor tube, the microbalance protected from sulfur dioxide and hot gases by flushing it with a dry nitrogen gas of $33.3 \mathrm{~mL} / \mathrm{s}$.

The morphological characterization of the samples was performed using a scanning electron microscope (SEM, JSM6380LV, JEOL Ltd, Tokyo, Japan) equipped with an energy dispersive X-ray spectrometer (EDS, Link Isis 3.0, Oxford Instrument plc, Oxon, U.K.), the particle size distribution performed using a particle size analyzer (Marstersizer 2000, Malvern Instruments Ltd., Malvern, UK). Also, the XRD patterns were obtained using a X-ray diffractometer (Rigaku D-max-2500PC, Rigaku/MSC, Inc., TX, U.S.A.) with $\mathrm{Cu} \mathrm{K} \alpha$ radiation $(\lambda=0.154 \mathrm{~nm})$ operated at $40 \mathrm{kV}$ and $30 \mathrm{~mA}$. And, samples before and after the oxidative roasting were analyzed for $\mathrm{Fe}, \mathrm{Si}$, and $\mathrm{S}$ by wet chemistry and for $\mathrm{Cu}, \mathrm{Zn}$, and $\mathrm{Pb}$ by the inductively coupled plasma (ICP) method (JY-38 plus, Horiba Ltd, Kyoto, Japan).
Table 1 Chemical compositions of the natural low grade zinc concentrate before and after being roasted. (mass \%)

\begin{tabular}{ccc}
\hline Chemical components & $\begin{array}{c}\text { Natural low grade zinc } \\
\text { sulfide concentrate }\end{array}$ & $\begin{array}{c}\text { * Roasted zinc sulfide } \\
\text { concentrate }\end{array}$ \\
\hline $\mathrm{Zn}$ & 28.4 & 33.8 \\
\hline $\mathrm{Fe}$ & 21.4 & 25.5 \\
\hline $\mathrm{Pb}$ & 0.5 & 0.5 \\
\hline $\mathrm{Cu}$ & 0.7 & 0.7 \\
\hline $\mathrm{Mn}$ & 1.9 & 2.2 \\
\hline $\mathrm{S}$ & 26.5 & 0.5 \\
\hline $\mathrm{SiO}$ & 7.0 & 8.4 \\
\hline $\mathrm{CaO}$ & 4.4 & 5.3
\end{tabular}

*The natural low grade zinc sulfide concentrate was roasted at $1073 \mathrm{~K}$ for 20 min under air.

Table 2 Particle size distribution of the natural low grade zinc concentrate and roasted product.

\begin{tabular}{ccc}
\hline \multirow{2}{*}{ Particle size $(\mu \mathrm{m})$} & $\begin{array}{c}\text { Natural low grade zinc } \\
\text { sulfide concentrate }\end{array}$ & $\begin{array}{c}\text { *Roasted zinc sulfide } \\
\text { concentrate }\end{array}$ \\
\cline { 2 - 3 } & Cumulation (mass\%) & Cumulation (mass\%) \\
\hline 0.42 & 1.39 & 0.64 \\
\hline 1.66 & 10.99 & 3.69 \\
\hline 4.37 & 21.98 & 7.78 \\
\hline 11.48 & 42.39 & 22.07 \\
\hline 22.91 & 61.58 & 45.14 \\
\hline 39.81 & 79.45 & 69.83 \\
\hline 60.23 & 91.32 & 86.40 \\
\hline
\end{tabular}

*The natural low grade zinc sulfide concentrate was roasted at $1073 \mathrm{~K}$ for 20 min under air.

\section{Results and Discussion}

\subsection{Characterization of samples}

A natural low grade zinc sulfide concentrate used was obtained after several mineral separation processes from Gagok mine in Korea. A chemical characterization of the low grade zinc sulfide concentrate, before and after being roasted, by wet chemistry and ICP methods was performed and Table 1 presents the chemical compositions. Table 1 shows the sample before being roasted mainly contains about $28.4 \%$ $\mathrm{Zn}, 21.4 \% \mathrm{Fe}$ and $26.5 \% \mathrm{~S}$ and after being roasted at $1073 \mathrm{~K}$ for $20 \mathrm{~min}$ under air $0.5 \%$ sulfur is only remained in the roasted sample.

The particle size distribution of the low grade zinc sulfide concentrate and roasted product were also performed using a particle size analyzer. Table 2 present about $60 \%$ of the mass of low grade zinc concentrate has a particle size less than $22.9 \mu \mathrm{m}$, while the concentrate roasted at $1073 \mathrm{~K}$ for $20 \mathrm{~min}$ under air has about $70 \%$ of its mass less than $39.8 \mu \mathrm{m}$. These results suggest that during the oxidative roasting of the low grade zinc concentrate the agglomeration of particles slightly occurs at the roasting temperature of $1073 \mathrm{~K}$ which is the highest temperature considered in the study. This is probably due to the presence of lead, copper and silica which have the ability of sintering. 


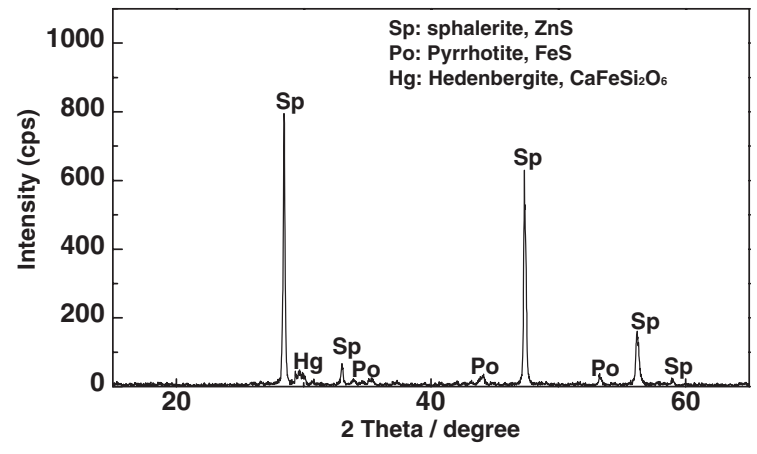

(a) The raw zinc sulfide concentrate

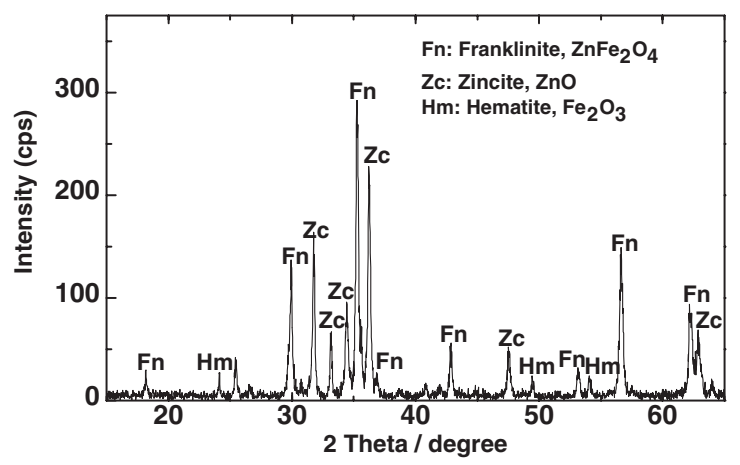

(b) The roasted zinc sulfide concentrate

Fig. 2 XRD patterns of the natural low grade zinc sulfide concentrate before and after being roasted at $1073 \mathrm{~K}$ for 20 min under air.

XRD patterns of the natural low grade zinc sulfide concentrate before and after the roasting reaction are presented in Fig. 2. As expected, the identified minerals for $\mathrm{Zn}$ and $\mathrm{Fe}$ were $\mathrm{ZnS}$ and $\mathrm{FeS}$ in the low grade zinc sulfide concentrate and $\mathrm{ZnO}, \mathrm{Fe}_{2} \mathrm{O}_{3}, \mathrm{Fe}_{3} \mathrm{O}_{4}$ and $\mathrm{ZnFe}_{2} \mathrm{O}_{4}$ in the concentrate roasted at $1073 \mathrm{~K}$ for $20 \mathrm{~min}$ under air. Also, samples before and after the roasting were examined by SEM (Fig. 3). The micrograph shows that the low zinc sulfide concentrate particles before the oxidative roasting are impervious as shown in Fig. 3(a), while after being roasted at $1073 \mathrm{~K}$ for $40 \mathrm{~min}$ under air, the produced concentrate particles are quite porous as shown in Fig. 3(b). It was thus guessed that the formation of metal oxides like zinc oxide and zinc-iron oxide compounds during the oxidative roasting begins at the outer particle surface as reported in the previous reseach. ${ }^{11)}$ However, it was very difficult to detect an interface dividing a zinc oxide shell from a core of nonoxidized zinc and iron sulfide since the size of the concentrate particles is relatively small.

\subsection{Interpretation of the rate data}

Figure 4 shows the TGA curve of the oxidative roasting of the low grade zinc sulfide concentrate obtained at a heating rate of $8 \mathrm{~K} / \mathrm{min}$ under air atmosphere. As shown in Fig. 4, the first weight loss of about $1.5 \%$ occurred in the temperature range $723-823 \mathrm{~K}$. Although the reason was not detail investigated because of the complication of the natural low grade zinc sulfide concentrate used in the study, it was only considered that one of the reasons might be the oxidation reaction of FeS. After the first weight loss stage, two-stage decrease occurred in the temperature range 823-1023 K. The

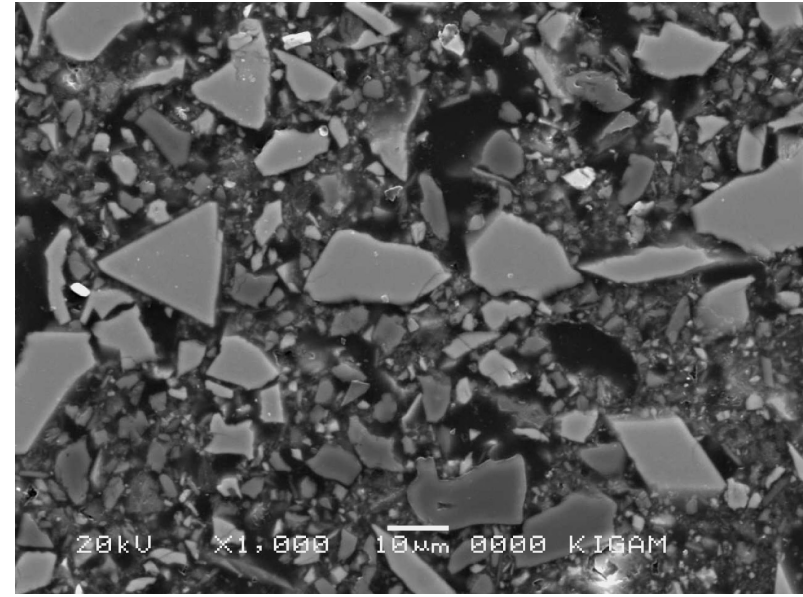

(a) Before the oxidative roasting

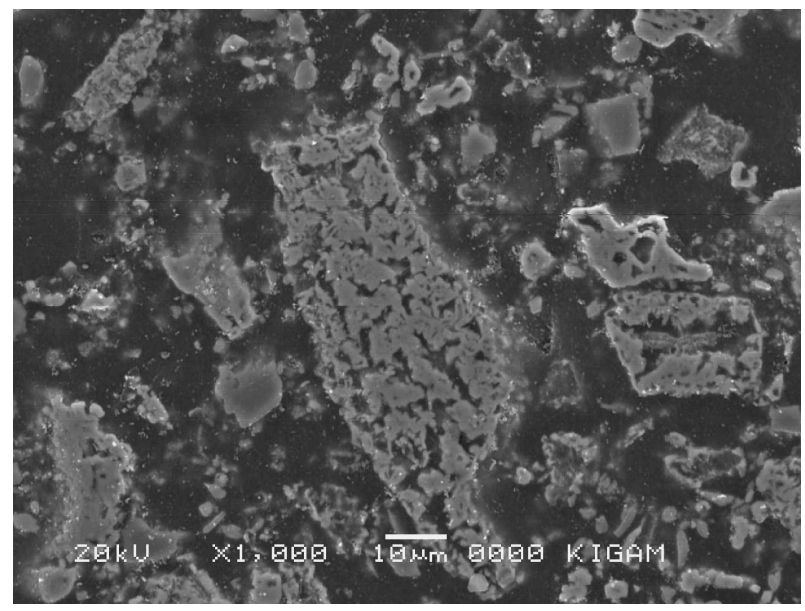

(b) After the oxidative roasting

Fig. 3 SEM of the zinc sulfide particles before and after being roasted at $1073 \mathrm{~K}$ for $40 \mathrm{~min}$ under air.

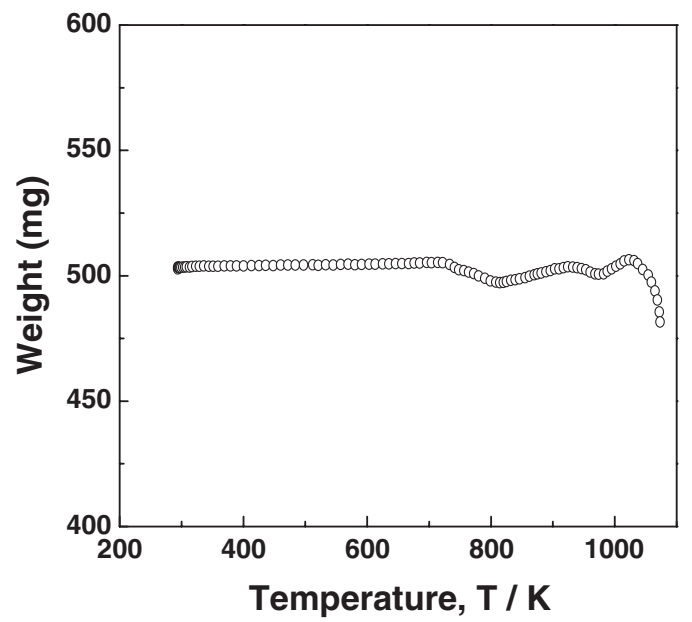

Fig. 4 A typical TGA curve of the oxidative roasting reaction of the natural low grade zinc sulfide concentrate obtained at a heating rate of $8 \mathrm{~K} / \mathrm{min}$ under air.

first weight increase might be mainly due to the formation of $\mathrm{FeSO}_{4} \cdot{ }^{10)}$ And then the weight decrease by its dissociation and the weight increase by the formation of $\mathrm{ZnSO}_{4}$ might 
follow. The similar phenomenon was reported by the kinetic study of a zinc sulfide concentrate produced from Maidanpek deposit in Yugoslavia. ${ }^{12)}$ However, it was very difficult in the study to detect the XRD patterns of the sulfate compounds such as $\mathrm{ZnSO}_{4}$ and $\mathrm{FeSO}_{4}$ at the samples produced in the oxidative roasting period. This might be the reason that even though the sulfate compounds form in the period as shown in Fig. 4, the amounts of the sulfate compounds produced are relatively small. It was thus considered in the oxidation reaction of the natural low grade zinc sulfide concentrate under air that the removal reaction of sulfur occurs mainly over $1023 \mathrm{~K}$.

Rate measurements for the oxidative roasting of the natural low grade zinc sulfide concentrate powder were carried out at temperature ranges between 998 and $1073 \mathrm{~K}$ under air. The experiments were continued until the initial input sample showed no noticeable further mass change. Kinetic analysis of the thermal data obtained was thus done in order to interpret the mechanism of the roasting reaction. In the present study, the removal ratio of sulfur from the natural low grade zinc sulfide concentrate at a particular time $\left(\mathrm{X}_{\mathrm{t}}\right)$ during the oxidative roasting was defined as:

$$
X_{\mathrm{t}}=X_{\mathrm{f}} \frac{W_{\mathrm{I}}-W_{\mathrm{t}}}{W_{\mathrm{I}}-W_{\mathrm{f}}}
$$

where $X_{\mathrm{f}}$ is the total removal ratio of sulfur at finishing the oxidative roasting, $W_{\mathrm{I}}$ is the initial weight $(\mathrm{mg})$ of sample, $W_{\mathrm{t}}$ is the weight $(\mathrm{mg})$ of sample at a particular time, and $W_{\mathrm{f}}$ is the weight $(\mathrm{mg})$ of sample at finishing the oxidative roasting. Here, the rates were measured by minimizing the effects of external mass transfer by using a sufficiently high flow rate $(16.7 \mathrm{~mL} / \mathrm{s})$ of air and small amount $(495-505 \mathrm{mg})$ of natural low grade zinc sulfide concentrate, which was chosen through the preliminary experiments.

The effect of reaction temperature on the oxidative roasting reaction rate was determined by varying the reaction temperatures between 998 and $1073 \mathrm{~K}$ under air, while all other experimental variables, such as sample mass and gas flow rate, were nearly identical for the measurement. The effect of reaction temperature on the oxidative roasting reaction rate is presented in Fig. 5. These curves show that the removal ratio of sulfur increases with increasing the reaction temperature. It is also seen that almost $95 \%$ of sulfur was removed in $20 \mathrm{~min}$ at $1073 \mathrm{~K}$.

In the present study, the removal ratio of sulfur until 0.90 was investigated for the kinetic analysis of the oxidative roasting reaction. The interpretation of the rate data was performed using a number of different rate equations including the nucleation and growth model and power law, from which spherical shrinking-core model with chemical reaction control proved to yield the best results. On the other hand, several researchers reported that the shrinking-core model was found to fit the reaction rate of sulfur removal for the oxidative roasting reaction of zinc sulfide concentrate. ${ }^{6,13)}$ The applicability of this rate expression can be expected from the fact that the porous zinc oxide and zinc-iron oxide particles during the oxidative roasting reaction are formed as shown in Fig. 3(b). In this rate expression, the removal ratio of sulfur is related to the oxidative roasting reaction time by ${ }^{14}$

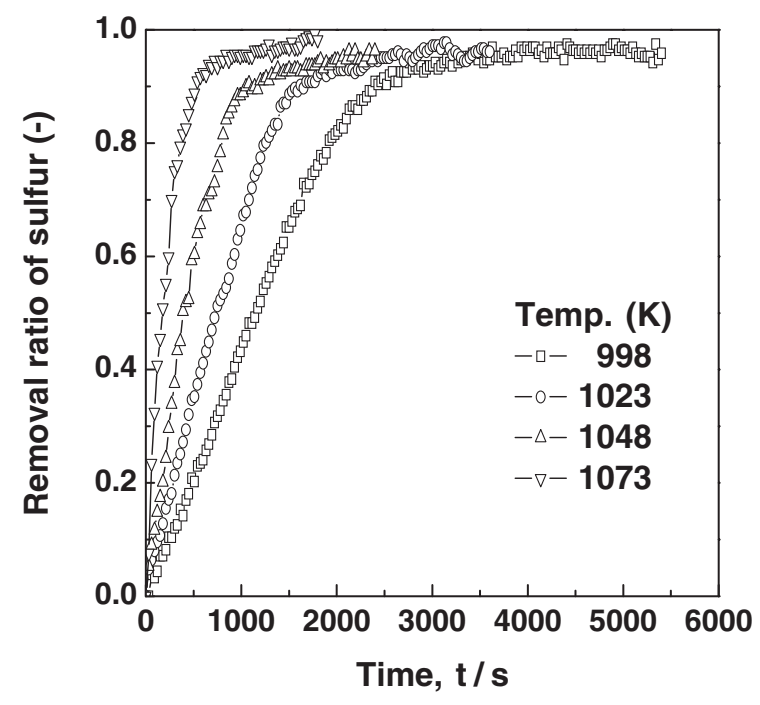

Fig. 5 Effect of reaction temperature on the oxidative roasting reaction of the natural low grade zinc sulfide concentrate under air.

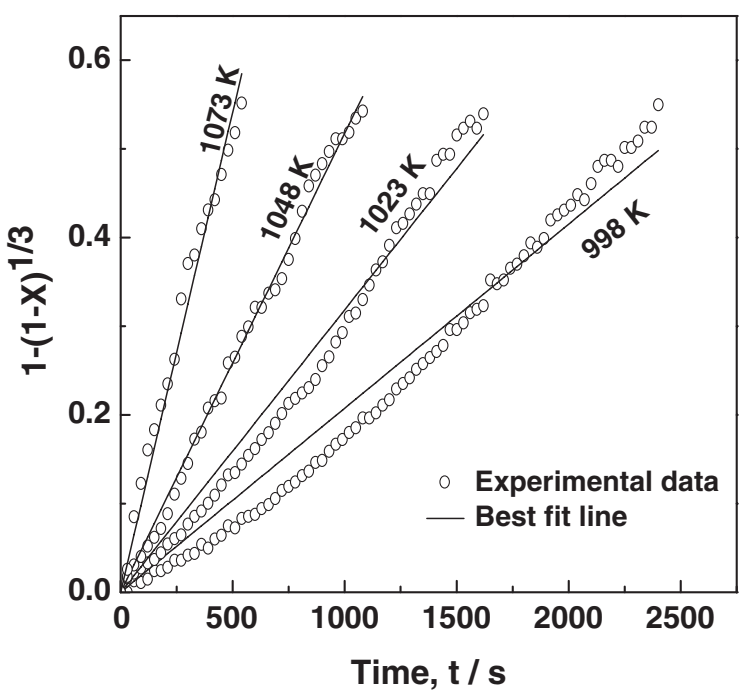

Fig. 6 Plot of the results in Fig. 5 according to eq. (2).

$$
1-(1-X)^{1 / 3}=k_{\mathrm{app}} t
$$

where $X$ is the removal ratio of sulfur, $t$ is the reaction time (s), and $k_{\text {app }}$ is the apparent rate constant $\left(\mathrm{s}^{-1}\right)$. It is apparent from eq. (2) that a plot of $1-(1-X)^{1 / 3}$ against $t$ should be linear with $k_{\text {app }}$ as the slope. The validity of the shrinkingcore model rate expression for the oxidative roasting of the natural low grade zinc sulfide concentrate with air was verified by first plotting the curves of Fig. 5 according to eq. (2), as shown in Fig. 6. Examination of the figure reveals that the rate data follow relatively well eq. (2). Although that, there are slightly disagreements between the experimental and fitting data due to the effect of the formation and dissociation of sulfate compounds like $\mathrm{ZnSO}_{4}$ and $\mathrm{FeSO}_{4}$ during the oxidative roasting as explained previously. In the Fig. 6, the values of the slopes were calculated by regression analysis. Here, straight lines with high-correlation coefficient $(r>0.994)$ were selected to represent the possible controlling mechanism. 


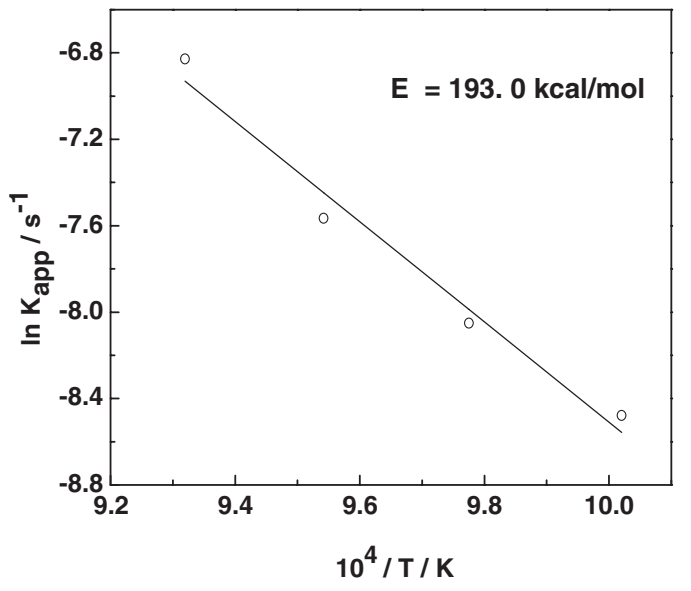

Fig. 7 Arrhenius plot of the rate constants obtained from the results of Fig. 5.

Figure 7 is an Arrhenius plot of the apparent rate constants. The slope of the straight line placed through the experimental points corresponds to an activation energy of $193.0 \mathrm{~kJ} / \mathrm{mol}(46.3 \mathrm{kcal} / \mathrm{mol})$, which is a little high when compared with the values reported in the literature. ${ }^{6,13)}$ This might be due to the characteristics of the natural zinc sulfide concentrate such as reactivity, porosity and chemical composition and difference of the oxidative roasting temperature. The high activation energy indirectly indicates that the oxidative roasting reaction of the natural low grade zinc sulfide concentrate with air is controlled by chemical reaction. Also, the line through the apparent rate constants can be expressed by the following equation:

$$
k_{\text {app }}=2.53 \times 10^{6} \cdot \exp \left[\frac{-23,212.7}{T}\right]\left(\mathrm{s}^{-1}\right)
$$

\section{Conclusion}

Oxidative roasting of the natural low grade zinc sulfide concentrate obtained from Gagok mine in Korea was performed in the temperature range 998-1073 K under air. The removal reaction of sulfur from the zinc sulfide concentrate by the oxidative roasting was found to occur mainly over $1023 \mathrm{~K}$. Also, almost $95 \%$ of sulfur contained in the natural low grade zinc sulfide concentrate was removed after the oxidative roasting at $1073 \mathrm{~K}$ for $20 \mathrm{~min}$. The spherical shrinking-core model for a chemical reaction control was applicable in describing the kinetics of the oxidative roasting reaction over the entire temperature range. The oxidative roasting reaction of the zinc sulfide concentrate under air has an activation energy of $193.0 \mathrm{~kJ} / \mathrm{mol}(46.3$ $\mathrm{kcal} / \mathrm{mol}$ ). The rate of the oxidative roasting of the zinc sulfide concentrate under air is represented by the following equation:

$$
\begin{gathered}
1-(1-X)^{1 / 3}=k_{\text {app }} t \\
\text { with } k_{\text {app }}=2.53 \times 10^{6} \cdot \exp \left[\frac{-23,212.7}{T}\right]\left(\mathrm{s}^{-1}\right)
\end{gathered}
$$

\section{Acknowledgement}

The authors would like to express special thanks to the Korea Institute of Energy Technology Evaluation and Planning, Energy/Resource R\&D Program of the Ministry of Knowledge Economy of Korea for financial support.

\section{REFERENCES}

1) Korea Zinc Company, Uljin-gun, Ulsan, Korea, private communication (August 2009).

2) F. Elgersma, G. J. Witkamp and G. M. Van Rosmalen: Hydrometallurgy 34 (1993) 23-47.

3) D. K. Xia and C. A. Pickles: Minerals Eng. 12 (1999) 693-700.

4) N. Leclerc, E. Meux and J. M. Lecuire: Hydrometallurgy 70 (2003) $175-183$.

5) J. M. Floyd and G. P. Swayn: Proc. Int. Sym. On Zinc and Lead Processing, ed. by J. E. Dutrizac, J. A. Gonzalez, G. L. Bolton and P. Hancock, (The Canadian Inst. Mining, Metallurgy and Petroleum, 1998) pp. 1-14.

6) C. A. R. Queiroz, R. J. Carvalho and F. J. Moura: Braz. J. Chem. Eng. 22 (2005) 127-133.

7) R. I. Dimitrov, N. Moldovanska, I. K. Bonev and Z. Zivkovic: Thermochim. Acta 362 (2000) 145-151.

8) J. W. Graydon and D. W. Kirk: Met. Trans. B 19B (1988) 141-146.

9) T. T. Chen and J. E. Dutrizac: JOM 56 (2004) 46-51.

10) B. S. Kim, E. Y. Kim, C. K. Kim, H. I. Lee and J. S. Sohn: Mater. Trans. 49 (2008) 1192-1198.

11) J. C. Balarini, L. D. O. Polli, T. L. S. Miranda, R. M. Z. D. Castro and A. Salum: Minerals Eng. 21 (2008) 100-110.

12) B. S. Boyanov, R. I. Dimitrov and Z. D. Zivkovic: Thermochim. Acta 296 (1997) 123-128.

13) Z. D. Zivkovic, D. Zivkovic, D. Grujicic, N. Strbac and V. Savovic: J. Thermal Anal. 54 (1998) 35-40.

14) H. Y. Sohn and M. E. Wadsworth: Rate Process of Extractive Metallurgy, (Plenum Press Inc., 1979) pp. 8-27. 